\title{
Experimental study on in-plane capacities of composite steel- concrete floor
}

\author{
P. Heng ${ }^{\mathrm{a} *}$, H. Somja ${ }^{\mathrm{a}}$, and M. Hjiaj ${ }^{\mathrm{a}}$ \\ ${ }^{a}$ LGCGM/Structural Engineering Research Group, INSA Rennes, France \\ *corresponding author, e-mail address: piseth.heng@insa-rennes.fr
}

\begin{abstract}
In steel frame structures, composite floor is an important element that plays a significant role in contributing to lateral stability. Its working role in the in-plane action is to transfer lateral loads, such as wind loads and seismic loads, to vertical load-resisting members. Such load transferring process depends on the in-plane capacities of the floor, which can be reduced after being subjected to explosion. However, the remaining capacities have not been previously studied yet in the literature. This paper presents an experimental investigation on the initial and residual in-plane capacities of the composite steel-concrete floor after being subjected to explosion, which was made within the RFCS research project BASIS:"Blast Action on Structures In Steel”. Large-scale experimental tests on four composite floor specimens, consisting of a reinforced concrete panel casted on a profile steel sheet Comflor, are performed to determine the in-plane capacities. The initial damaging of the composite floor caused by the explosion is reproduced by a flexural test using a quasi-static loading. In the in-plane shear tests, special connections between the rigid frames of the shear rig and the embedded bolts in the concrete are used to ensure a good transferring of the applied load. The results from this experimental study are the first insights on the behavior of the composite floor with and without initial predamaging. They can also be useful for a preliminary recommendation to estimate residual in-plane capacities (stiffness and resistance) of the composite floor after being subjected explosion.
\end{abstract}

Keywords: Composite steel-concrete floor; Residual in-plane shear capacities; Largescale experimental tests; Explosion.

\section{Introduction}

The composite slab has become increasingly more popular for its benefits over traditional reinforced concrete slab, mainly the erection time and cost saving. The advantages of the composite floor system have been mentioned in many research reports [1-4]. It is inferred in those reports that the composite floor system provided at least two important features over a traditionally reinforced concrete slab. For one thing, in the composite slab system, steel decks are used to possibly provide formworks during the casting stages of the topping concrete. Such an application makes it possible to save more time in formwork installation. Furthermore, the steel deck is also viewed to have an ability to function like a tension reinforcement in composite action of the system under positive bending.
The composite floor was first introduced in the 1950s and the main concern at those times was solely related to the gravity-load capacity, as stated by Easterling and Porter [1]. However, there exist also lateral loads such as forces due to wind or seismic event. That being said, the floor system working as a diaphragm takes part in resisting the lateral loads by distributing the in-plane load to the frame system. Due to its important working role, the in-plane characteristics of the slab should be rigorously studied in addition to its characteristics regarding to gravity load.

The in-plane characteristics of the thin panel can be investigated using different types of typical shear test fixtures such as Rail Shear fixture, Picture Frame Shear fixture, Cantilever, and Three Points [5]. The picture frame test has been used to determine in-plane stiffness of 
various material types, ranging from textile to steel plate as found in [6-8]. The technique of the picture frame test consists of a frame or fixture of four stiff members, attaching to each and every edge of a square or rectangular specimen and being applied with a uniaxial force at two diagonally opposite corners of the frame [8]. The frame is also pinned at all of its corners so that the bending moment occurring at each corner is not resisted. The use of picture frame test to obtain shear stiffness of gypsum, fiberboards and combinations of other nonstructural roofing system by Mastrogiuseppe et al [9] led to the understanding that the picture frame test can be applied to many types of thin panel of various materials. Such fixture, also called a shear testing rig, is also used in other references such as [3, 10-12] as to acquire the in-plane characteristics of the composite walling system and the profiled steel sheeting. However, the picture frame fixture is most of the time constructed in a small scale, the configuration of whom is detailed in [3]. Since it is preferable to have a full-scale test of composite slab under in-plane shear load, a composite diaphragm test [1] and a cantilever diaphragm test [2] have been proposed in the literature. Such configurations allow the usage of a full-scale specimen. Rafiei et al [13] recently adapted the composite diaphragm test and the picture frame test to investigate the behavior of a composite walling system consisting of two skins of profiled steel sheeting and an infill of concrete subjected to in-plane impact loading using large-scale specimens. Yet, such an adaptation has not been done for the case of a composite slab with profile steel sheet. The adapted configuration of the test can indeed be used to acquire the information of the in-plane capacities of the composite slab.

The objective of this paper is to determine the initial and residual in-plane capacities of the composite floor with profile steel sheet after being damaged by an uplifting caused by blast action. In this paper, a newly adapted configuration of the large-scale in-plane shear test is presented. The initial damage caused by the explosion is experimentally reproduced by a flexural test using a quasi-static loading.

\section{Experimental plan}

The following experimental plan was defined. First, two composite floor specimens were submitted to in-plane shear tests at INSA Rennes in order to find their initial shear stiffness. The shear force was limited to $50 \mathrm{kN}$ in order not to initiate any crack on the specimen. The results for the two specimens were not conclusive because the low value of the force made it impossible to obtain a stable value of the displacement. Hence, an additional third specimen was made with newly casted concrete and tested up to collapse without predamaging by explosion. The results obtained were used as a reference. Next, the two specimens were sent to Institut National de l'Environnement Industriel et des Risques (INERIS) for the explosion test to generate damage due to blast. After being exposed to explosion, the two specimens were delivered back to INSA Rennes to perform the tests in order to determine the residual shear stiffness and the ultimate shear resistance of the specimen.

Unfortunately, the explosion tests at INERIS had completely destroyed the composite specimens, making it impossible to test them for residual stiffness. As a result, it was decided to alter the experimental plan. An additional fourth specimen was made with newly casted concrete and used in a supplementary flexural test that quasi-statically reproduces the predamaging on the specimen. The damaged specimen was then tested for the residual stiffness and the ultimate shear resistance.

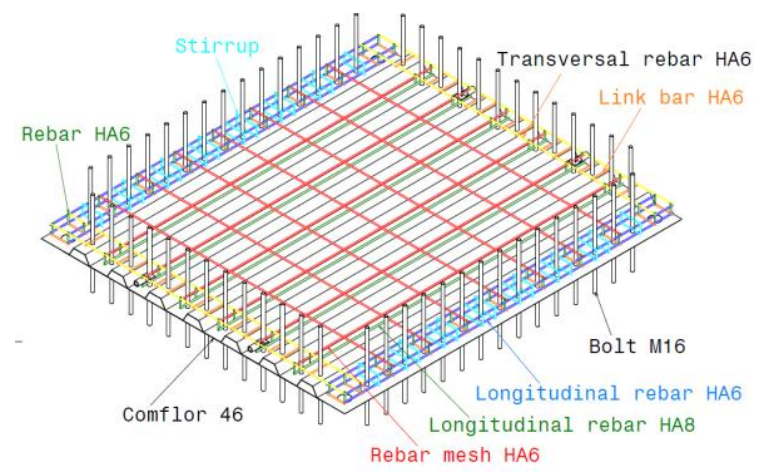

Fig. 1. Composite floor specimen.

\section{Specimen and material properties}

The composite beam specimen was defined with regard to a reference building given in a European project called Blast Action on Structures in Steel (BASIS), with some necessary adaptations following the installation capacities of the laboratory at INERIS.

Illustrated in Fig. 1, the specimen was composed of a composite floor with two steel 
profile sheets Comflor and $56 \mathrm{M}-16$ bolts. The composite floor, with the dimension of 1800 mm-by-2000 $\mathrm{mm}$ and the thickness of $100 \mathrm{~mm}$, was fabricated by casting concrete of a $\mathrm{C} 25 / 30$ type on a corrugated steel sheeting Comflor 46 whose nominal yield limit was $280 \mathrm{MPa}$ (supplied by Tata Steel) with a HA-6 mm meshed reinforcement. The steel sheetings were overlapped each other without welding. The rebars of diameter $6 \mathrm{~mm}$ and $8 \mathrm{~mm}$ had a nominal yield strength of $500 \mathrm{MPa}$. A more detail on the adaptation of the specimen and the material properties of each component in the specimen are described in [14]. The supplementary third and fourth specimens were cast separately with new concrete material. The characteristics of the concrete at the time of the tests (on 10/06/2015 for the initial inplane shear test on the third specimen without predamaging, and on 16/02/2016 and 04/03/2016 for the flexural test and residual inplane shear test on the fourth spe-cimen, respectively) are presented in Table 1 .

Table 1. Characteristics of concrete from cylinder tests

\begin{tabular}{|c|c|c|c|c|}
\hline Specimen & Test date & $\begin{array}{c}\text { Ages } \\
\text { (days) }\end{array}$ & $\begin{array}{c}\mathbf{f}_{\mathbf{c}} \\
(\mathbf{M P a})\end{array}$ & $\begin{array}{c}\mathbf{f}_{\mathrm{cm}} \\
(\mathbf{M P a})\end{array}$ \\
\hline \multirow{3}{*}{$3 \mathrm{rd}$} & \multirow{3}{*}{$10 / 06 / 2015$} & \multirow{3}{*}{117} & 34.17 & \multirow{3}{*}{34.48} \\
\hline & & & 34.09 & \\
\hline & & & 35.20 & \\
\hline \multirow{3}{*}{4 th } & $16 / 02 / 2016$ & 566 & $\begin{array}{l}48.92 \\
48.79\end{array}$ & 48.85 \\
\hline & \multirow[b]{2}{*}{$04 / 03 / 2016$} & \multirow[b]{2}{*}{583} & 48.27 & \multirow[b]{2}{*}{47.96} \\
\hline & & & $\begin{array}{l}48.26 \\
48.35 \\
\end{array}$ & \\
\hline
\end{tabular}

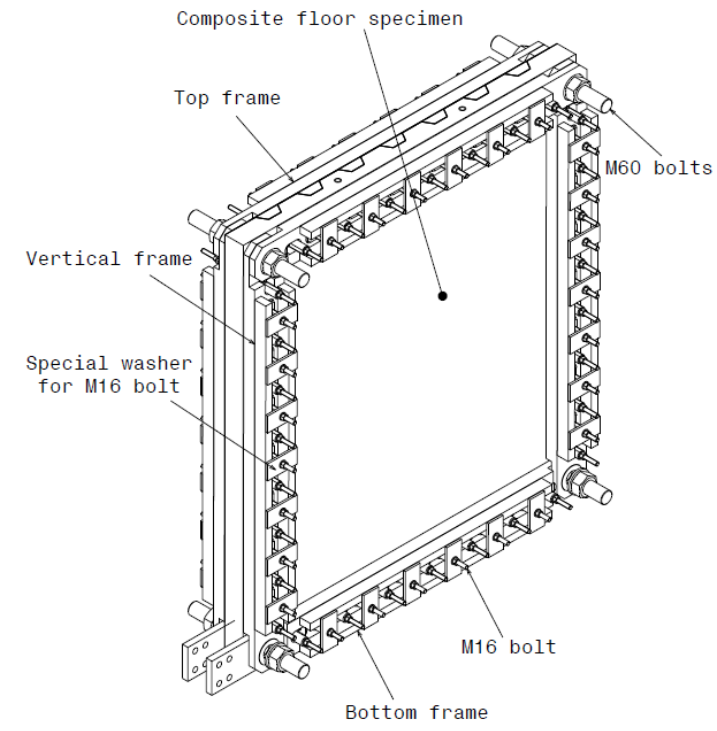

Fig. 2. Specimen with rigid frames.

\section{In-plane shear test: experimental set- up and loading procedure}

As illustrated in Fig. 2, the composite floor is bolted along its four edges to rigid frames with 15 bolts of type M16 at the edge sides of 2 $\mathrm{m}$ and 13 bolts at the edge sides of $1.8 \mathrm{~m}$. Each member of the rigid frame has a U-shape crosssection with a height of $120 \mathrm{~mm}$, the dimensions of which are shown in Fig. 3. These rigid frames are pinned at each and every corner of the composite floor panel by M-60 bolts.

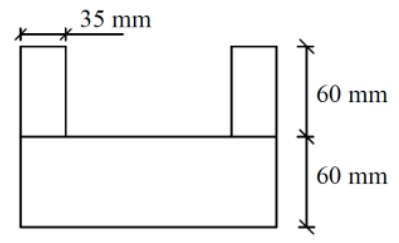

Fig. 3. U-shape cross-section of frame.

As illustrated in Fig. 4, the set of the composite floor specimen and the rigid frames is positioned vertically on a rigid frame system ( mesh floor and reacting frame system). Having one end fixed to the reacting frame by bolts, a hydraulic servo controlled actuator applied a horizontal load on one of the top M-60 pins of the specimen. This force jack had a load capacity of $500 \mathrm{kN}$ for the initial and residual stiffness test and $1500 \mathrm{kN}$ for the residual ultimate resistance test. The bottom M-60 pins of the specimen were fixed with the supporting rigid frame system and restrained from horizontal displacements by a steel profile.

The M-16 bolts were embedded inside the concrete and passed through holes in the Comflor in order to have immediate contact. On the other hand, the contact between the M-16 bolts and the U-shape rigid frames is ensured by a special contact system, as shown in Fig. 5 . This contact system comprised a tube with an internal diameter of $15 \mathrm{~mm}$ and external diameter of $40 \mathrm{~mm}$, a M-10 bolt, a demi-round steel piece and a round steel plate. The tube was placed inside an oval slotted hole in the Ushape frames whereas the M-10 bolt was welded to the demi-round steel piece that was in contact with the inside a surface of the frame hole, and placed inside and along the slotted hole. The contact was made by screwing the M10 not with an oversized length. This contact system was necessary considering the deformations provoked by the initial blast and flexural tests. 


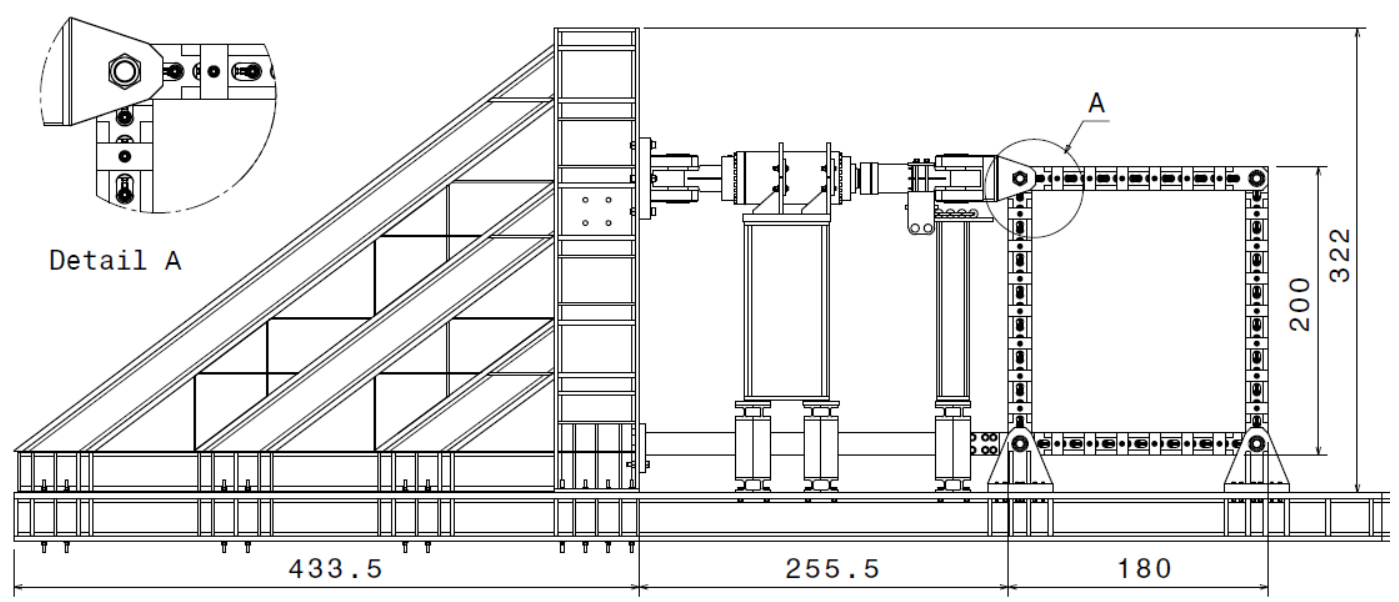

Fig. 4. Test setup of the in-plane shear test.

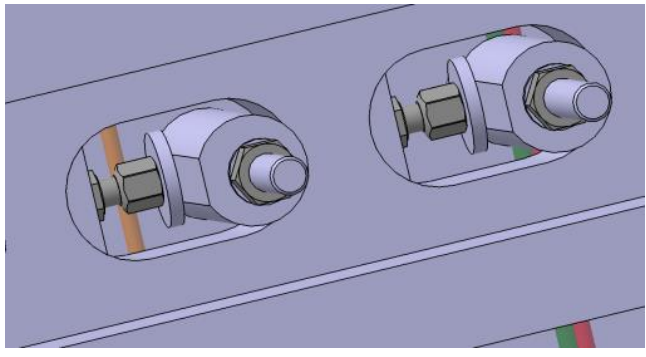

Fig. 5. Special contact system.

The estimation of the collapse load of the specimen was done using the approach in the literatures [11,15-17]. The methods by Easley and McFarland [15] was used to find the critical load for which the steel profile sheeting alone can resist and by Kupler and Gestle [16] to evaluate the critical load for which the composite panel as a whole can withstand, respectively. From the critical load, the maximum load to apply in the initial test and test after explosion is then determined.

In order to define the sensitivity needed for the measurements, the horizontal displacement of the panel was calculated by using theoretical formulas and compared with the displacement in the experiments made by Rafiei [17] and by Haussain and Wright [11]. At last, the horizontal displacement is compared to the diagonal elongation causing first crack of the panel.

The estimated collapse load [15-16] was obtained with a value of $\mathbf{6 0 8} \mathbf{~ k N}$. From this value, a maximum admissible load in a service limit state was approximated by a value of $\mathbf{3 0 0}$ kN. In this limit state, the concrete was allowed to crack to some extent. To avoid any concrete cracking, the applied load for the initial test is obtained with a value of $\mathbf{5 0} \mathbf{~ k N}$ by dividing the limit state admissible value with an arbitrary coefficient 4 to have a better confidence. The corresponding displacement was estimated to $0.06 \mathrm{~mm}$.

The experimental load displacement curves by Rafiei [17] could not be used due to insufficiently immediate contact of their test setup. However, he announced the first crack of his specimen at a load of $30 \mathrm{kN}$, which was converted to $90 \mathrm{kN}$ in our case considering the ratio of the dimensions between his specimen and ours. In addition, by using the load displacement diagram by Haussain and Wright [11], the shear displacement for the limited force was approximately $0.2 \mathrm{~mm}$. Also, the displacement determined from the cracking limit by a tension action in diagonal direction was about $0.36 \mathrm{~mm}$. Hence, the limited displacement of $0.06 \mathrm{~mm}$ in our current test was well conservative.
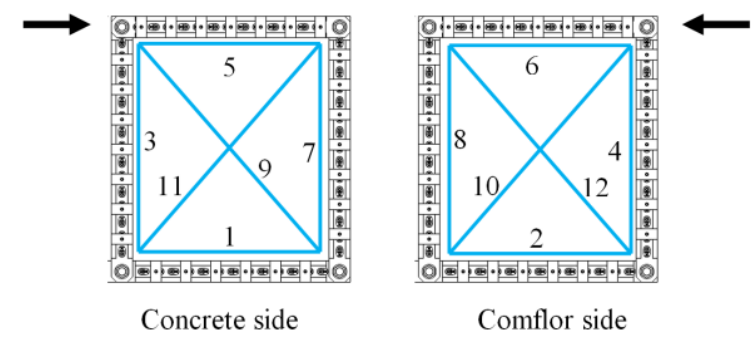

Fig. 6. Wire sensors and their references.

In the initial in-plane shear stiffness test, 5 cycles of loading and unloading procedure between 0 and $50 \mathrm{kN}$ were applied. In the ultimate resistance test, the load was increasingly applied until the collapse of the specimen.

Wire sensors with the capacity of $+/-2.5$ $\mathrm{mm}$ were used to measure the in-plane deformations of the specimen. For the tests up to the collapse, sensors along diagonals were re- 
placed by sensors with a capacity of $+/-75 \mathrm{~mm}$. The sensors were installed around the edges and along the two diagonals of the specimen at both the concrete and Comflor sides, as shown in Fig. 6.

\section{Flexural test: experimental set-up and loading procedure}

It can be inferred from the results of the numerical simulations of blast tests on the specimen, which were done by Tecnalia within the BASIS project, that the inertia effect is negligible. Hence, to reproduce the pre-damage of the explosion, a supplementary flexural test that applies a quasi-static load on the specimen was suggested. The experimental setup of the flexural test is illustrated in Fig. 7. In this setup, the composite floor specimen was placed horizontally on two IPE-240 support beams on concrete side. These beams are hinged to the UPN-220 potelets to allow the rotations of the beams so that the reactions to the specimen are always perpendicular.

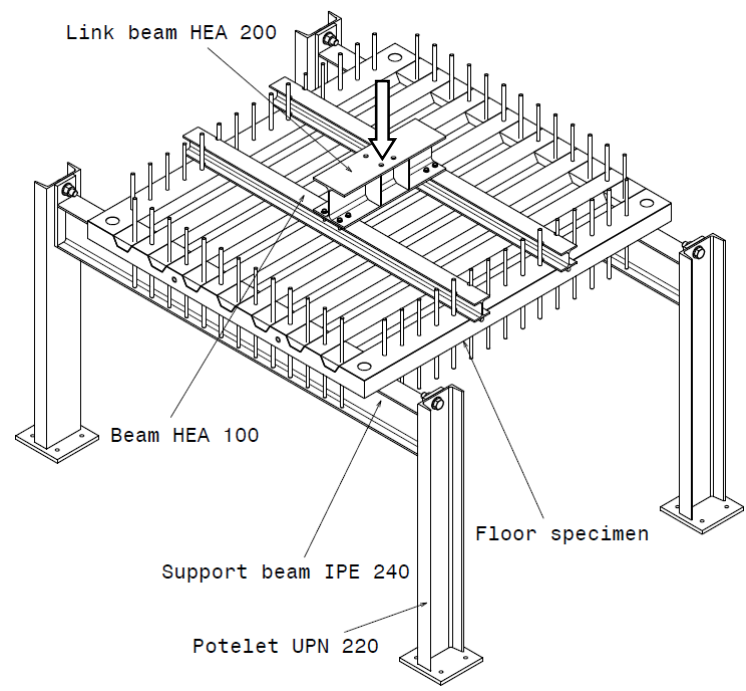

Fig. 7. Flexure test setup.

In order to produce two loading pin lines on the specimen, two HEA-100 beams were placed on the floor through a contact of two profiles in-between (Fig. 8). These two beams were parallel to the support beams and attached to another HEA-200 steel beam, which is submitted to a downward action by a force jack.

The global displacement of the specimen is measured at the midpoint, applied load points, under joints and at the supports.

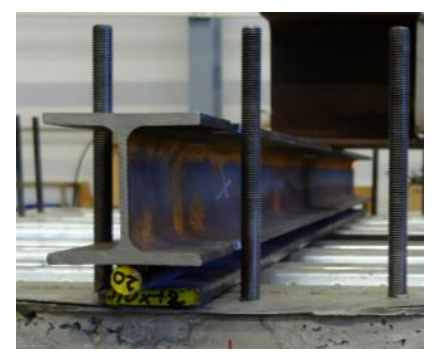

Fig. 8. Pin contact.

\section{Flexural test: results}

The flexural test was applied to the fourth specimen to initial a pre-demaging. Fig. 9 illustrates the global force-displacement curve.

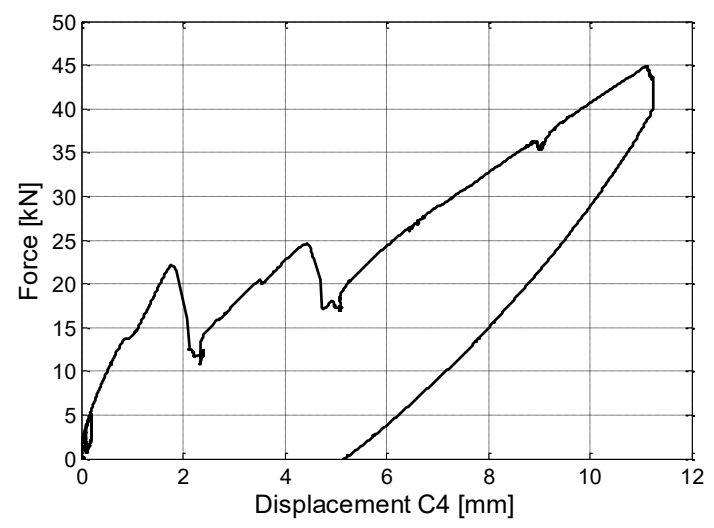

Fig. 9. Flexural test: force-dispalcement curve.

Two major cracks along the direction $\mathrm{Y}$ ( the span direction perpendicular to the supporting beam direction) and two major crack along the direction $\mathrm{X}$ (the supporting beam direction) were detected simultaneously during loading at about $22 \mathrm{kN}$. A sudden drop of the load could be observed when the cracks abruptly appeared. A sudden fall of load was again noted from around $24 \mathrm{kN}$ to $17 \mathrm{kN}$ when the length of existing cracks grew larger and a few new cracks appeared and joined the old cracks. The loading was stopped once the opening of cracks had reached a width larger than $1 \mathrm{~mm}$. The maximum load attained is read up to $43.72 \mathrm{kN}$, which corresponds to the displacement of 10.42 $\mathrm{mm}$.

\section{In-plane shear test: results}

Two specimens had been tested for initial inplane shear stiffness for a limited force of 50 $\mathrm{kN}$. As expected, the results were unfortunately not conclusive because the complex system in the setup required to create a pure shear state in the specimen made it impossible to obtain a 
stable value of the displacements for a low force as low as $50 \mathrm{kN}$.

As a consequence, the third specimen without pre-damaging was tested up to collapse. The maximum load attained was $638.4 \mathrm{kN}$. In addition, the first crack (Fig. 10) appeared in a diagonal direction at an applied load of $290 \mathrm{kN}$ with a top horizontal displacement of $16.1 \mathrm{~mm}$.

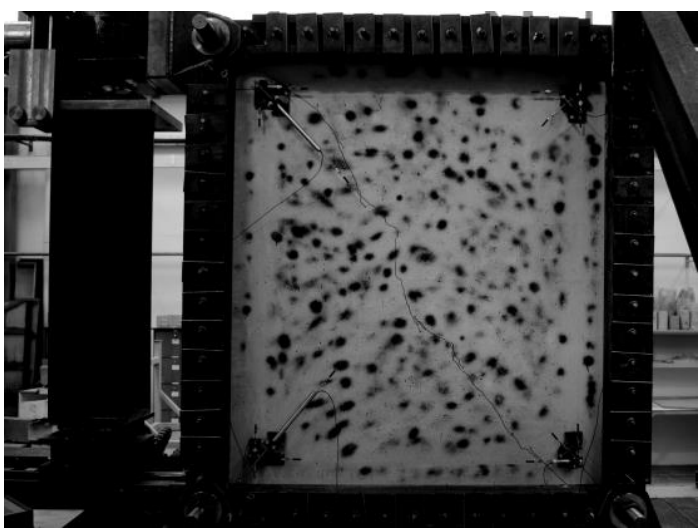

Fig. 10. First diagontal crack $(\mathrm{F}=290 \mathrm{kN})$ for specimen without predamaging.

As the load was progressively increased more diagonal cracks developed over the whole specimen. As could be observed during the test, the ultimate load was attained when the steel sheet buckled. This buckling was followed immediately by a local crushing of the concrete in the buckling zone, and the load brutally decreased.

The in-plane shear test was also applied to the damaged specimen damaged by the flexural test. It was observed that the initial cracks (see Fig. 11) produced by flexural test started to open at around $205 \mathrm{kN}$. The debonding between concrete panel and steel sheeting was assumed by cracking sounds during the loading at about $245 \mathrm{kN}$. The first diagonal crack was visually spotted near bottom corner on the side of reaction wall (edge 3) at $315 \mathrm{kN}$. It was followed by another crack which is found very close to top corner (edge 2). The main diagonal crack could be detected only at $565 \mathrm{kN}$. The buckling of steel sheeting was observed at 665 $\mathrm{kN}$ when a gap between the overlapping steel sheetings opened larger. The maximum load attained is recorded at approximately $670 \mathrm{kN}$. The concrete failed completely (Fig. 12.b) at a force jack displacement of about $80 \mathrm{~mm}$. It was followed immediately by a local out of plane buckling of the steel sheet at the top of the overlapping region (Fig. 12.a).

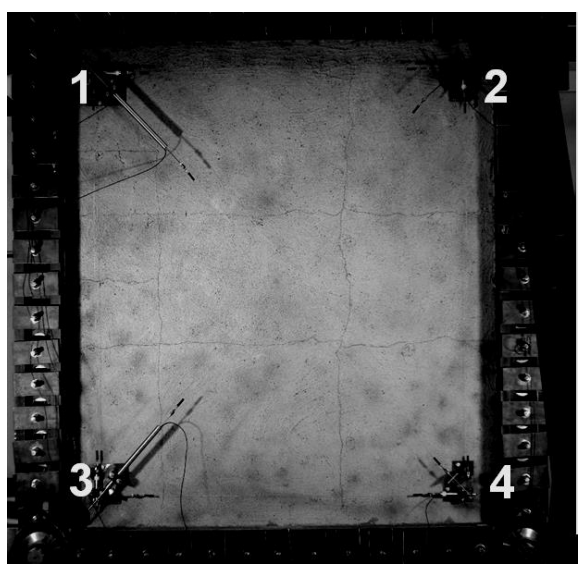

Fig. 11. First diagontal crack $(\mathrm{F}=290 \mathrm{kN})$ for specimen with predamaging.
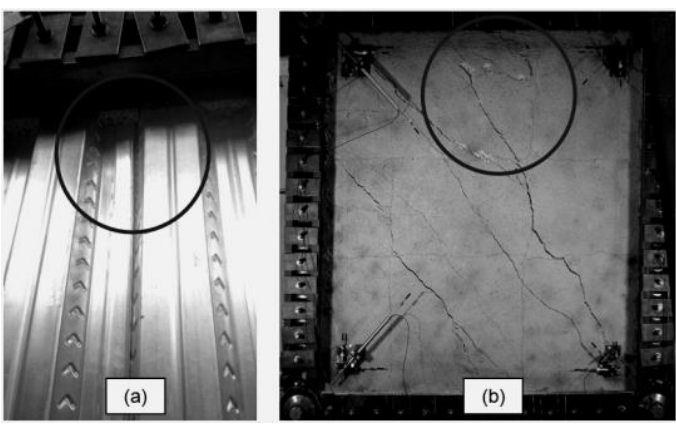

Fig. 12. (a). Buckling of steel sheet. (b). Failure of concrete.

Fig. 13 shows the evolutions of the force in function of the distortion angle at Comflor side for both the specimens with and without the pre-damaging. From this figure, it can be inferred that both specimens attained nearly the same yielding load with a visible but short plateau before the collapse of the specimen by steel buckling or concrete crashing. The small difference in the maximum load might be bound to the difference in the concrete strength. It can be noticed that the in-plane stiffness of the composite floors between the two tests is relatively the same.

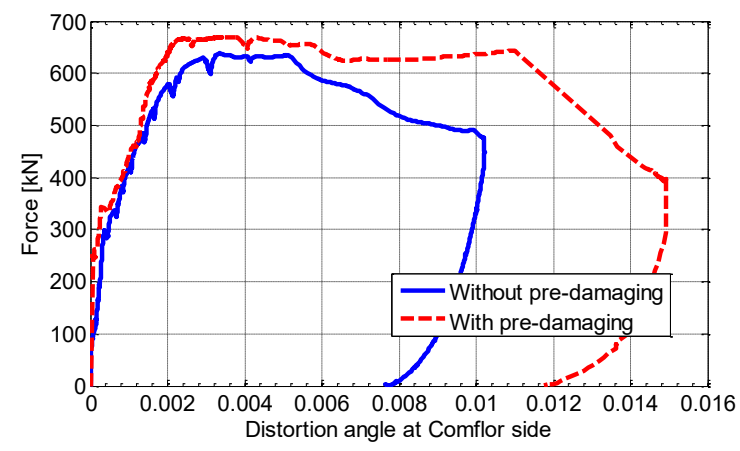

Fig. 13. Force-distortion curve: comparison. 


\section{Conclusion}

This paper presents an experimental investtigation on the initial and residual in-plane shear capacities of composite floors after being damaged by an uplift provoked by explosion. These shear capacities are determined by performing large-scale in-plane shear tests. The pre-damaging is reproduced by a flexure test.

The pre-damaging resulting in a major cracking of concrete with openings up to $1 \mathrm{~mm}$ has not induced a reduction in the shear resistance nor in stiffness of the composite floor. It is therefore interesting to further investigate the case of a more severe pre-damaging either by more experimental tests or numerical simulations.

\section{References}

[1] Easterling WS, Porter ML. Steel deck reinforced concrete diaphragms. I. ASCE: Journal of Structural Engineering 1994;120(2):560-576.

[2] Porter ML, Greimann LF. Composite steel deck diaphragm slabs - design modes. Sixth international specialty conference on coldformed steel structures; 1982.

[3] Hossain KMA. In-plane Shear Behavior of Composite Walling with Profiled Steel Sheeting. Doctoral thesis. University of Strathclyde: Glasgow, U.K; 1995.

[4] Porter ML, Ekberg Jr CE. Compendium of ISU Research Conducted on Cold-Formed Steel-Deck Reinforced Slab System. Enginerring Research Institute: Iowa State University; 1978.

[5] Farley G, Baker D. In-plane shear test of thin panels. Experimental Mechanics 1983;23(1):8188.

[6] Peng XQ, Cao J, Chen J, Xue P, Lussier DS, Liu L. Experimental and numerical analysis on normalization of picture frame tests for composite materials. Composites Science and Technology 2004;64(1):11-21.

[7] Harrison P, Clifford MJ, Long AC. Shear characterisation of viscous woven textile composites: a comparison between picture frame and bias extension experiments. Composites Science and Technology 2004;64(10-11):14531465.

[8] Bush HG, Weller T. A Biaxial Method for Inplane Shear Testing. National Aeronautics and Space Administration: Hampion, Virginia; 1978.

[9] Mastrogiuseppe S, Rogers CA, Tremblay R, Nedisan CD. Influence of nonstructural components on roof diaphragm stiffness and fundamental periods of single-storey steel buildings. Journal of Constructional Steel Research 2008;64(2):214-227.

[10] Hossain KMA, Wright HD. Performance of Profiled Concrete Shear Panels. Journal of Structural Engineering 1998;4(124):368-381.

[11] Hossain KMA, Wright HD. Experimental and theoretical behaviour of composite walling under in-plane shear. Journal of Constructional Steel Research 2004;60(1):59-83.

[12] Wright HD, Hossain KMA. In-Plane Shear Behavior of Profiled Steel Sheeting. Thin Wall Structure 1998;29:79-100.

[13]Rafiei S, Hossain KMA, Lachemi M, Behdinan $\mathrm{K}$. Impact shear resistance of double skin profiled composite wall, In Engineering Structures 2017;140:267-285.

[14]Heng P, Bud M, Somja H, Hjiaj M, Battini JM, Residual stiffness and strength of shear connectors in steel-concrete composite beams after being subjected to a pull-out pre-damaging: An experimental investigation. Structures 2017;11:189-205.

[15] Easley JT, McFarland. Buckling of light-gage corrugated metal shear diaphragms. Journal of Structural Division 1969;95:1497-1516.

[16] Kupfer HB, Gerstle KH. Behaviour of Concrete Under Bi-axial Stresses. Journal of Engineering Mechanics Division 1973;99:853-866.

[17]Rafiei, S., Behaviour of Double Skin Profiled Composite Shear Wall System under In-plane Monotonic, Cyclic and Impact Loadings, in Civil Engineering. Ryerson University: Toronto, Ontario, Canada; 2011. 